\title{
Effect of Ultrasonic Power on Microstructure and Mecha- nical Properties of Mg-3RE-3Zn-0.7Y Alloy
}

\author{
Fang Xiaogang, Wu Shusen, Zhao Li, Lü Shulin, An Ping
}

State Key Laboratory of Materials Processing and Die \& Mould Technology, Huazhong University of Science and Technology, Wuhan 430074,

China

\begin{abstract}
The Rare Earth (RE) contained Mg cast alloys have large potential in heat-resistant applications, if the RE-rich intermetallic compounds can be refined during the casting process. In the present research, the effect of ultrasonic vibration (USV) with different powers on the microstructure and the mechanical properties of the semi-solid Mg-3RE-3Zn-0.7Y alloys has been investigated. The $\mathrm{Mg}$ alloy melt at temperature of $20 \sim 40{ }^{\circ} \mathrm{C}$ above the liquidus was exposed to USV for $90 \mathrm{~s}$ at different powers from $800 \mathrm{~W}$ to $1200 \mathrm{~W}$, and the exposure was ended at about $10^{\circ} \mathrm{C}$ below the liquidus. The results show that a good semi-solid slurry with fine and spherical $\alpha-\mathrm{Mg}$ particles can be obtained, and the primary $\alpha$-Mg crystals have an average particle size of $55 \mu \mathrm{m}$ and average shape coefficient of 0.63 after USV with $1000 \mathrm{~W}$ power. After USV treatment with the power of $1000 \mathrm{~W}$, the ultimate tensile strength and the elongation of the cast samples increase by $25.2 \%$ and $93.5 \%$, respectively, compared with those of the samples without USV treatment. It can be concluded that ultrasonic vibration is a good method to prepare semi-solid slurry of $\mathrm{Mg}$ alloy with fine and relatively round primary crystals due to cavitation and acoustic streaming effects.
\end{abstract}

Key words: Mg-3RE-3Zn-0.7Y alloy; ultrasonic power; semi-solid slurry; microstructure; mechanical property

As a new kind of structural materials, magnesium alloys are increasingly in demand due to their low density, high specific strength and stiffness, good thermal conductivity, attractive damping property, excellent electromagnetic shielding and good castability ${ }^{[1]}$. However, it is necessary to enhance the strength and corrosion-resistance of the $\mathrm{Mg}$ alloy in order to expand its usage and utilized amount. One of the important methods for strengthening and toughening the magnesium alloys is Rare Earth (RE) alloying. Currently, the standard alloys of RE contained $\mathrm{Mg}$ alloys are mainly Mg-Zn-RE and $\mathrm{Mg}-\mathrm{RE}-\mathrm{Zr}$ alloys, of which the contents of RE are from $2.5 \%$ to $4.0 \%$. There are some recent researches concerning about alloys using RE as the main alloying elements, such as $\mathrm{Mg}-\mathrm{Gd}-\mathrm{Y}$ and $\mathrm{Mg}-\mathrm{Nd}-\mathrm{Zn}-\mathrm{Zr}^{[2]}$. As possessing special valence electron structure, some heavy RE elements have big solid solubility in magnesium resulting in forming effective strengthening phase, thus greatly improving their properties at room temperature and high temperature. Since RE elements become important elements of magnesium alloys with high strength, heat-resistance, and corrosion-resistance, the direction of the high-performance $\mathrm{Mg}$ alloys containing $\mathrm{RE}$ have become a significant direction of the research and development of $\mathrm{Mg}$ alloys ${ }^{[3]}$.

Grain refinement or non-equilibrium structure achievement is an important way for strengthening and toughening of magnesium alloys, as well as improving the capability of plastic deformation. As an effective and pollution-free grain refinement technique, ultrasonic vibration (USV) can significantly refine solidification microstructure $^{[4,5]}$. The USV process is mainly used in producing semi-solid slurry of aluminum alloys. Wu and Lü et al ${ }^{[4-6]}$ prepared semi-solid slurry of aluminum alloy by direct and indirect USV process. Their results indicated

\footnotetext{
Received date: January 14, 2015

Foundation item: National Natural Science Foundation of China (51275183); Research Fund for Doctoral Program of Higher Education of China (20120142110002) Corresponding author: Wu Shusen, Ph. D., Professor, State Key Laboratory of Materials Processing and Die \& Mould Technology, Huazhong University of Science and Technology, Wuhan 430074, P. R. China, Tel: 0086-27-87556262, E-mail: ssw636@ hust.edu.cn

Copyright (C) 2016, Northwest Institute for Nonferrous Metal Research. Published by Elsevier BV. All rights reserved.
} 
that good semi-solid slurries of $\mathrm{Al}$ alloys could be obtained in a short time by applying USV near their liquidus temperatures, and a considerable improvement in the mechanical properties was achieved after squeeze casting.

Researches on ultrasonic treatment of Mg-RE alloys are seldom. Most of studies mainly focus on some commercially used magnesium alloys, such as AZ91 (Mg-9Al-1Zn alloy). The results of Liu's studies showed that ultrasonic treatment resulted in the formation of fine non-dendritic grains, and the tensile and compressive strengths as well as the fracture strains of the castings were improved ${ }^{[7,8]}$. Gao et al studied the effect of ultrasonic power from $0 \mathrm{~W}$ to $700 \mathrm{~W}$ on the microstructure and the mechanical properties of AZ91 alloy. It was indicated that globular and refined grains were obtained when AZ91 alloy was subject to high intensive ultrasonic vibration and the grain size was decreased gradually from 202 $\mu \mathrm{m}$ to $146 \mu \mathrm{m}$ as the ultrasonic power increased. Besides, the mechanical properties of the alloy were improved accordingly ${ }^{[9]}$. Most researches on ultrasonic treatment of magnesium alloys were focused on grain refinement, but the studies on the preparation of semi-solid slurry and rheocasting of $\mathrm{Mg}$ alloy via USV process were scarce.

In the present work, semi-solid slurry of Mg-3RE-3Zn-0.7Y magnesium alloy in which RE was used as the main alloying elements was prepared. The effect of USV power on the microstructure was investigated and the mechanical properties of cast samples were examined.

\section{Experiment}

The schematic of USV apparatus is shown in Fig.1. It consists of an ultrasonic generator with a maximum power of $1.8 \mathrm{~kW}$ and frequency of $20 \mathrm{kHz}$, an amplitude transforming rod, a heating furnace, a PID temperature controller, a metallic cup, etc. The vibrating time and rest-work ratio can be adjusted by the ultrasonic generator. The rest-work ratio $R_{\mathrm{t}}$ of vibration was defined as the ratio of interval resting time $T_{\mathrm{r}}$ to ultrasonic time $T_{\mathrm{w}}$ in an ultrasonic vibration cycle, i.e., $R_{\mathrm{t}}=$

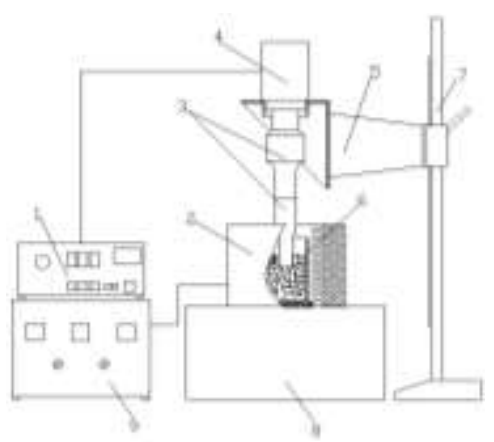

1-ultrasonic generator, 2-heating furnace, 3-amplitude transforming rod, 4-transducer, 5-viberator holder, 6-metal cup, 7-slide bar, 8-holding table, 9-PID temperature controller

Fig.1 Schematic of experimental unit
$T_{\mathrm{w}} / T_{\mathrm{r}}$. In the present investigation, $R_{\mathrm{t}}=1, T_{\mathrm{r}}=1.0 \mathrm{~s}$ and $T_{\mathrm{w}}=$ $1.0 \mathrm{~s}$ were selected.

The chemical composition (wt\%) of the Mg-RE-Zn-Y magnesium alloy was 3RE, 3Zn, 0.7Y, 0.6Zr, and balance $\mathrm{Mg}$. The misch metal RE was composed of $65 \% \mathrm{Ce}$ and $35 \% \mathrm{La}$. The liquidus and the solidus temperatures of this alloy are 645 and $545{ }^{\circ} \mathrm{C}$, respectively. About $4 \mathrm{~kg}$ of the alloy was melted firstly in a low-carbon steel crucible at $720{ }^{\circ} \mathrm{C}$ under an atmosphere containing a gas mixture of $1 \% \mathrm{SF}_{6}$ and $99 \% \mathrm{~N}_{2}$ (volume fraction). The metallic cup was preheated to $550{ }^{\circ} \mathrm{C}$ in the heating furnace simultaneously. Subsequently, about $300 \mathrm{~mL}$ (about $550 \mathrm{~g}$ ) of the melt was poured into the metallic cup, then the vibration rod was immersed into the melt $15 \mathrm{~mm}$ to $20 \mathrm{~mm}$ from the surface. The melt was treated by USV starting at $670{ }^{\circ} \mathrm{C}$ under four different ultrasonic powers: $0 \mathrm{~W}$ (no USV), $800 \mathrm{~W}$ (power density of $2.67 \mathrm{~W} / \mathrm{mL}$ ), $1000 \mathrm{~W}$ $(3.33 \mathrm{~W} / \mathrm{mL})$, and $1200 \mathrm{~W}(4.0 \mathrm{~W} / \mathrm{mL})$. The power density $\left(\rho_{\mathrm{w}}\right)$ was defined as follows:

$$
\rho_{\mathrm{w}}=P / V
$$

where, $P$ is the ultrasonic power. $V$ is the volume of the melt.

In order to prevent the melt from oxidation, argon gas was introduced as the protective atmosphere during the slurry preparation process. After vibrated for $90 \mathrm{~s}$ the melt cooled to the semi-solid temperature of $635 \sim 639^{\circ} \mathrm{C}$, and some slurry with certain solid fraction was extracted out by a quartz tube with an inner diameter of $6 \mathrm{~mm}$ and quenched in water immediately. The remaining slurry was poured into a cast iron mold preheated to $200{ }^{\circ} \mathrm{C}$, to get tensile-test samples with diameter of $8 \mathrm{~mm}$ (Fig.2).

Specimens over $10 \mathrm{~mm}$ in length were cut from the quenched rods for microstructure observation and metallographic analysis. After the specimens were polished and etched by $4 \%$ (volume fraction) nitric acid ethanol solution, several metallographs of each specimen were taken by an Axiovert 200MAT optical microscope and a JSM-7600 scanning electron microscope (SEM). Micrographs of the samples were analyzed using a quantitative metallographic analysis software ${ }^{[10]}$. The shape coefficient $\left(S_{\mathrm{F}}\right)$ of a non-dendritic particle in the present study was defined as follows:

$$
S_{\mathrm{F}}=4 \pi A / L_{\mathrm{P}}^{2}
$$

where, $A$ is the sectional area of a particle in a micrograph, and $L_{\mathrm{P}}$ is the circumference. $S_{\mathrm{F}}$ varies from 0 to 1 , and when the value of $S_{\mathrm{F}}$ is close to 1 , the sectional shape of the particle approaches to a circle. The average shape coefficient $S_{\mathrm{F}}$ of particles was calculated out by the software, based on counting all primary particles in a photograph.

The size of the primary non-dendritic $\alpha-\mathrm{Mg}$ crystals was characterized by average particles diameter $d$ and measured by Heyn's linear intercept method, i.e., $d$ was defined as follows:

$$
d=V_{\mathrm{f}} L_{\mathrm{T}} / N
$$

where, $V_{\mathrm{f}}$ is the volume fraction of primary particles. $L_{\mathrm{T}}$ is the overall length of measured lines used in the software for one 
metallograph, and $N$ is the number of particles passed through by the measured lines.

The dimensions of a cylindrical tensile specimen are shown in Fig.2, and the room temperature tensile tests were conducted on a WDW3200 tester, the average ultimate tensile strength (UTS) value and the average elongation were obtained from three samples for each specified condition.

\section{Results and Discussion}

\subsection{Effect of USV on microstructure of Mg-3RE-3Zn- 0.7Y Slurry}

Fig. 3 shows the quenched microstructures of Mg-3RE-3Zn$0.7 \mathrm{Y}$ slurry treated by different ultrasonic powers. From Fig. 3 it is seen that the microstructure of the alloy in semi-solid state consists of primary $\alpha-\mathrm{Mg}$ particles which are distributed in the matrix, and the solid volume fractions are between 33\% 42\%. The matrix is formed due to the solidification of the remaining liquid in the semisolid slurry during water quenching. Comparing Fig.3a and $3 b$, it is clear that the size and the morphology of primary $\alpha-\mathrm{Mg}$ particles are influenced significantly by USV. Without USV (Fig.3a), the $\alpha$-Mg phase in the slurry shows a coarse dendrite shape, demonstrating the normal dendritic growth mode. After USV with the power of

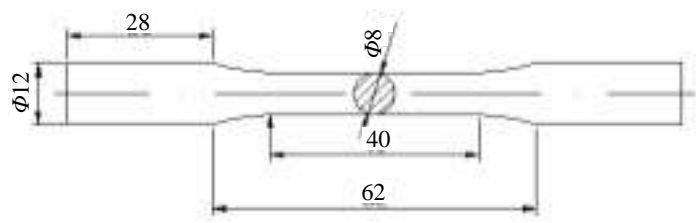

Fig.2 Dimensions of tensile specimens (in $\mathrm{mm}$ )

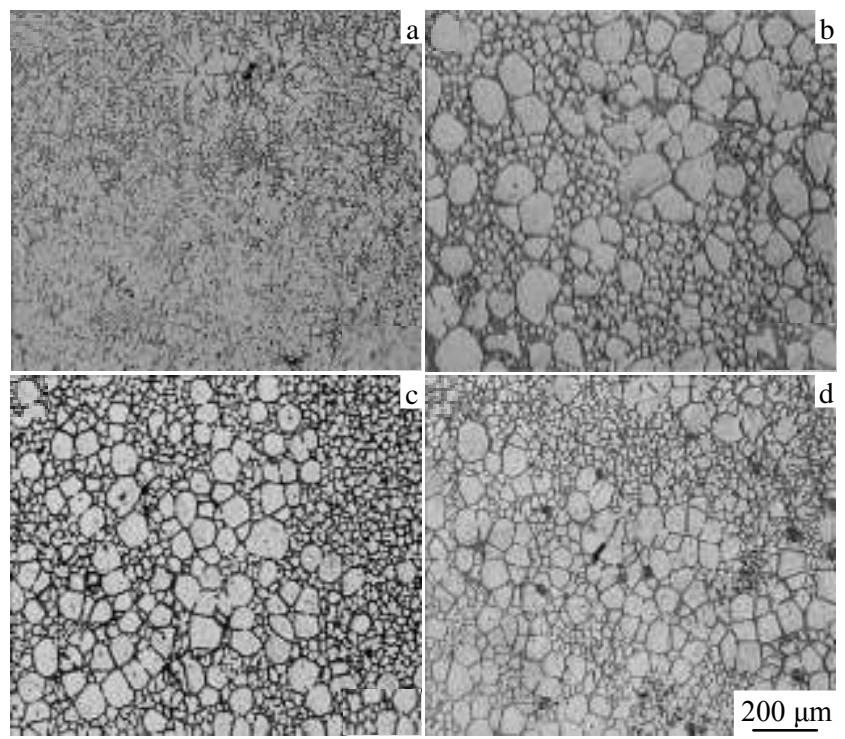

Fig.3 Water-quenched microstructures of Mg-3RE-3Zn-0.7Y slurry treated by different ultrasonic powers: (a) $0 \mathrm{~W}$, (b) $800 \mathrm{~W}$, (c) $1000 \mathrm{~W}$, and (d) $1200 \mathrm{~W}$
$800 \mathrm{~W}$ (Fig.3b), the $\alpha-\mathrm{Mg}$ phase becomes fine and spherical particles and is uniformly dispersed in the matrix. Fig.4 shows the influence of ultrasonic power on the average size and shape factor of the particles. As can be seen, with the increasing of the ultrasonic power from $800 \mathrm{~W}$ to $1000 \mathrm{~W}$, the particle size of primary $\alpha$-Mg crystals decreases from $71 \mu \mathrm{m}$ to $55 \mu \mathrm{m}$ and the average shape factor increases from 0.56 to 0.63 . When the ultrasonic power increases to $1200 \mathrm{~W}$, the grain size increases slightly from $55 \mu \mathrm{m}$ to $59 \mu \mathrm{m}$, and the shape factor is 0.57 , slightly smaller than 0.63 .

In the making process of semi-solid slurry by ultrasonic vibration, nucleation begins at a certain temperature between the liquidus and solidus when the molten melt is cooled down from liquid state. The refinement and spheroidization of the primary $\alpha-\mathrm{Mg}$ phase may be mainly attributed to the cavitation and the acoustic streaming induced by USV. Cavitation refers to the phenomenon of formation, growth and collapse of micro-bubbles under an ultrasonic field. Cavitation effect caused by ultrasonic vibration can affect nucleation from two aspects. On one hand the cavitation may activate the infusible inclusions in the melt, such as tiny oxides or intermetallic compounds, and they become the matrix for heterogeneous nucleation. On the other hand, during the growth period the micro-bubbles expand and the melt evaporates inside the bubbles. The evaporation and the expansion decrease the temperature of the micro-bubbles; therefore undercooling happens around the micro-bubbles surfaces and makes these bubbles as the sources of nuclei ${ }^{[4,11]}$. When the sound pressure becomes bigger, the critical radius of acoustic cavitation bubbles is smaller and the amount of micro-bubbles in the melt becomes larger. Therefore, a high ultrasonic power leads to a high sound pressure and helps to refine grains ${ }^{[12]}$

The acoustic pressure gradient formed in the propagation of ultrasound leads to the acoustic streaming effect. In the presence of acoustic streaming, temperature and solute are distributed uniformly throughout the bulk melt, and the solute concentration at the solidification front is removed, so that the nuclei almost have the same growth velocity in all directions

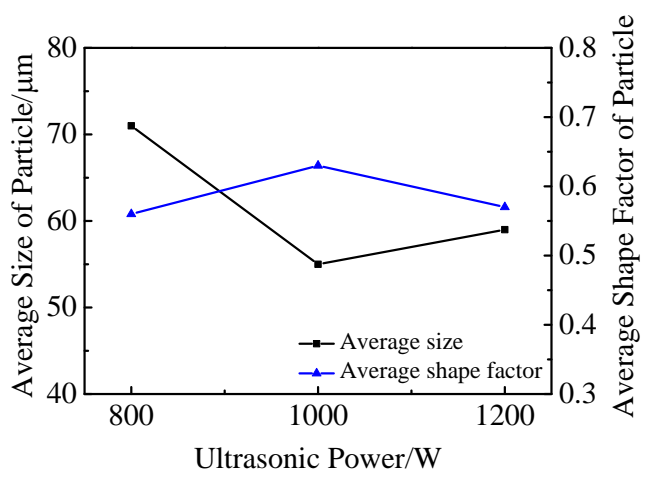

Fig.4 Influence of ultrasonic power on average size and shape factor of particles 
and the dendritic growth of the nuclei is restricted ${ }^{[6]}$. The value of ultrasonic power determines the maximum amplitude of the end face of the amplitude transforming rod, so the velocity of acoustic streaming increases with the increase of ultrasonic power $^{[12]}$. Compared with the situation without USV, USV application leads to more heat-loss and bigger cooling rate because of the convection and diffusion effect. So the cooling rate also increases with the ultrasonic power increasing from $800 \mathrm{~W}$ to $1000 \mathrm{~W}$. However, when the ultrasonic power continues to increase to $1200 \mathrm{~W}$, excessive energy is introduced and converted into heat in the melt, thereby reducing the cooling rate of the melt and prolonging the time for grain growth, which is negative for grain refinement ${ }^{[13]}$. Therefore, when treated with the ultrasonic power of $1200 \mathrm{~W}$, the average size of primary $\alpha-\mathrm{Mg}$ particles increases slightly, and the average shape factor decreases.

\subsection{Effect of USV on microstructure of gravity cast samples}

Fig.5a shows the microstructure of the gravity cast sample without USV treatment. As can be seen, typical primary $\alpha-\mathrm{Mg}$ dendrites are observed. Fig.5b shows the microstructure of Mg-3RE-3Zn-0.7Y alloy treated with an ultrasonic power of $800 \mathrm{~W}$. It is clear that non-dendritic primary $\alpha-\mathrm{Mg}$ particles are uniformly dispersed in the casting. Similar to the USV rheocasting processing of aluminium alloy ${ }^{[14]}$, there are two-type distinct particles with different sizes. For ease of description, the relatively larger grains with an average particle diameter (APD) of $75 \mu \mathrm{m}$ are called primary $\alpha_{1}-\mathrm{Mg}$ particles while the smaller ones with an APD of $32 \mu \mathrm{m}$ called primary $\alpha_{2}-\mathrm{Mg}$ particles.

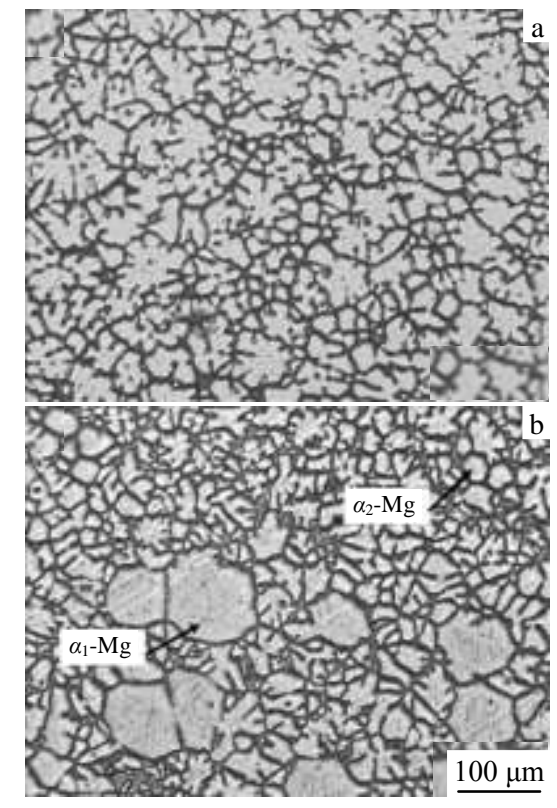

Fig.5 Microstructure of gravity cast sample without USV treatment (a) and Mg-3RE-3Zn-0.7Y alloy treated with ultrasonic power of $800 \mathrm{~W}$ (b)
There are distinct two solidification stages in the rheocasting process. The solidification of the melt at the stage of USV treatment to make semisolid slurry is referred to as the first solidification, while the solidification of the slurry during pouring and in the cast iron mold is referred to as the secondary solidification. At the first solidification stage, the cavitation caused by USV enhances heterogeneous nucleation in the melt As a result of forced convection generated by cavitation and acoustic streaming, the majority nuclei are formed at the early stage of USV treatment. These spherical $\alpha-\mathrm{Mg}$ grains formed during the first solidification are marked as first primary non-dendritic particles $\left(\alpha_{1}-\mathrm{Mg}\right)$. Because of acoustic streaming effect, temperature and solute are uniformly distributed throughout the bulk melt, and nuclei formed at the last stage of USV treatment have not enough time to grow into crystals and survive in the remaining liquid. When the slurry is poured into the metallic mold, heterogeneous nucleation occurs again in the remaining liquid because of the relatively low temperature of the mold. All these nuclei, formed at the last stage of USV treatment and during pouring, grow and accomplish solidification within a short time, thereby producing the fine and spherical $\alpha-\mathrm{Mg}$ particles. These fine and spherical $\alpha-\mathrm{Mg}$ grains formed during the secondary solidification are marked as secondary primary non-dendritic particles $\left(\alpha_{2}-\mathrm{Mg}\right)$. Compared with rheo-squeeze casting process, lower cooling rate in gravity casting leads to a rosette growth for the $\alpha_{2}$ particles rather than spherical ${ }^{[14]}$.

Fig.6a shows the solidification microstructure of semi-solid slurry of Mg-3RE-3Zn-0.7Y produced with USV. After the USV treatment, the microstructure is composed of small spherical primary $\alpha$-Mg particles and intermetallic compounds

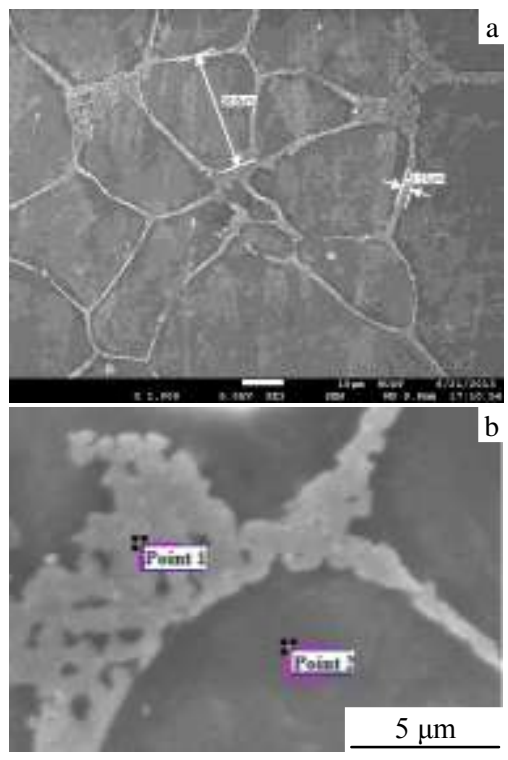

Fig.6 SEM solidification microstructure (a) and EDS analysis points (b) of semi-solid slurry of Mg-3RE-3Zn-0.7Y produced with $1000 \mathrm{~W}$ 
along the crystal interface. Fig.6b is the magnification of local area in Fig.6a, and the EDS results of points 1 and 2 are shown in Table 1. The compositions of point 2 of primary $\alpha-\mathrm{Mg}$ particles are mainly $\mathrm{Mg}$ element and a small amount of solid-solution $\mathrm{Zn}$ element. The $\mathrm{O}$ element in the result is caused by oxidation of the metallographic samples in air after polishing. The intermetallic compounds along the crystal interface are composed of rare-earth elements $\mathrm{Ce}, \mathrm{La}, \mathrm{Y}, \mathrm{Mg}$ and $\mathrm{Zn}$. Therefore they are intermetallic compounds of Mg-RE-Zn-Y.

As rare-earth elements $\mathrm{Ce}$ and $\mathrm{La}$ have very little solubility in $\mathrm{Mg}$ crystals, $\mathrm{Ce}$ and $\mathrm{La}$ are easy to react with $\mathrm{Mg}$ to form compounds in the melt:

$$
\mathrm{Mg}+\mathrm{Ce}=\mathrm{Mg}_{12} \mathrm{Ce}
$$

$\mathrm{Mg}+\mathrm{La}=\mathrm{Mg}_{12} \mathrm{La}$

On the basis of formation of bi-elements compounds $\mathrm{Mg}_{12} \mathrm{Ce}$ or $\mathrm{Mg}_{12} \mathrm{La}, \mathrm{Zn}$ and $\mathrm{Y}$ in the remanent melt are also easy to enter them to form Mg-RE-Zn-Y multi-elements compounds. Besides, as $\mathrm{Zr}$ has almost the same lattice constant with $\mathrm{Mg}$, it can be the heterogeneous nuclei for $\mathrm{Mg}$ crystals, and it is not detected out in the EDS because of its rare amount.

\subsection{Effect of USV on mechanical properties of gravity casting samples}

The mechanical properties of cast samples are shown in Fig.7. It can be known that with the increase of ultrasonic power, ultimate tensile strength and elongation first increase and then decrease. The samples treated by USV with the power of $1000 \mathrm{~W}$ have the maximum mechanical properties, of which the maximum ultimate tensile strength (UTS) and elongation are $144 \mathrm{MPa}$ and $4.45 \%$, respectively. Compared with the samples without USV (the UTS is $115 \mathrm{MPa}$ and the elongation is $2.3 \%$ ), the UTS and elongation of the samples

Table 1 Composition of compounds and matrix at various points in Fig.6b by EDS (wt\%)

\begin{tabular}{ccccccc}
\hline Element & $\mathrm{Mg}$ & $\mathrm{Zn}$ & $\mathrm{Ce}$ & $\mathrm{La}$ & $\mathrm{Y}$ & $\mathrm{O}$ \\
\hline Point 1 & 45.71 & 21.27 & 11.23 & 8.47 & 3.92 & 9.4 \\
Point 2 & 88.97 & 1.18 & - & - & - & 9.85 \\
\hline
\end{tabular}

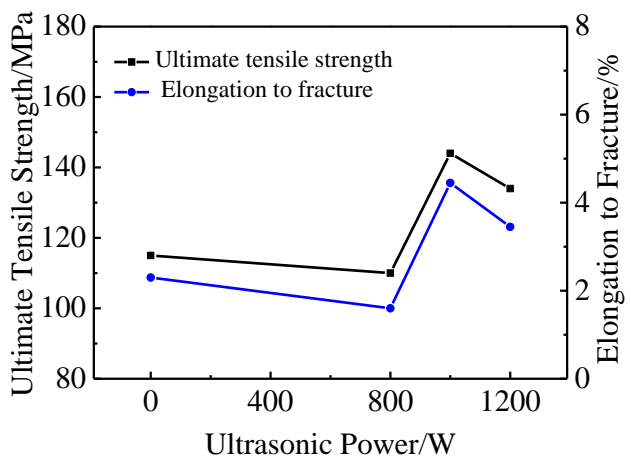

Fig.7 Influence of ultrasonic power on mechanical properties treated with the ultrasonic power of $1000 \mathrm{~W}$ increase by $25.2 \%$ and $93.5 \%$, respectively. However, the samples treated with the power of $800 \mathrm{~W}$ have relatively lower mechanical properties. This may be due to the larger grain size and the existence of defects such as porosity. When the ultrasonic power is $1200 \mathrm{~W}$, the mechanical properties decrease slightly because the average grain size is larger than that of $1000 \mathrm{~W}$.

Ultrasonic vibration is effective for the refinement and spheroidization of particles, which is beneficial to improve the mechanical properties of the alloy. The refinement and the spheroidization of the microstructure could be mainly attributed to the cavitation and acoustic streaming induced by USV, and the acoustic streaming homogenizes the solute field and eliminates the macro-segregation. Therefore, ultrasonic vibration with an optimized power can significantly improve the mechanical properties of Mg-3RE-3Zn-0.7Y alloy.

\section{Conclusions}

1) The USV has a significant effect on the refinement and spheroidization of primary $\alpha-\mathrm{Mg}$ particles of $\mathrm{Mg}-\mathrm{RE}-\mathrm{Zn}-\mathrm{Y}$ alloys at the nucleation stage, which is mainly attributed to the cavitation and acoustic streaming induced by the USV. Good semisolid slurry with fine and spherical solid particles can be obtained within $90 \mathrm{~s}$ by applying USV with a power of 1000 $\mathrm{W}$, and the average size and the shape coefficient of primary $\alpha-\mathrm{Mg}$ particles are $55 \mu \mathrm{m}$ and 0.63 , respectively.

2) Compared with the microstructures of the gravity cast samples without USV treatment, the primary $\alpha$-Mg particles of the samples treated by USV become fine and spherical. There are distinct two-type particles $\left(\alpha_{1}-\mathrm{Mg}\right.$ and $\left.\alpha_{2}-\mathrm{Mg}\right)$ different in size, which are formed in two solidification stages.

3) The microstructure of this semi-solid alloy is composed of small spherical primary $\alpha-\mathrm{Mg}$ particles and Mg-RE-Zn-Y intermetallic compounds along the crystal interface.

4) After USV treatment, the samples treated with a power of $1000 \mathrm{~W}$ have the maximum tensile strength and elongation, which are increased by $25.2 \%$ and $93.5 \%$, respectively compared to the samples without USV.

\section{References}

1 Easton M, Beer A, Barnett M et al. Journal of the Minerals Metals and Materials Society[J], 2008, 60(11): 57

2 Ding W J, Zeng X Q. Acta Metallurgica Sinica[J], 2010, 46(11): 1450 (in Chinese)

3 Zeng X Q. Acta Metallurgica Sinica[J], 2010, 46(9): 1041 (in Chinese)

4 Lü S L, Wu S S, Zhu Z M et al. Materials Science and Engineering $A[\mathrm{~J}], 2011,528: 8635$

5 Lü S L, Wu S S, Zhu Z M et al. Transactions of Nonferrous Metals Society of China[J], 2010, 20(S): 758

6 Wu S S, Lü S L, An P et al. Materials Letters[J], 2012, 73: 150

7 Liu X B, Osawa Y, Takamori S et al. Materials Science and Engineering $A[\mathrm{~J}], 2008,487: 120$ 
8 Liu X B, Osawa Y, Takamori S et al. Materials Letters[J], 2008, 62: 2872

9 Gao D M, Li Z J, Han Q Y et al. Materials Science and Engineering $A[\mathrm{~J}], 2009,502: 2$

10 Wu S S, Xie L Z, Zhao J W et al. Scripta Materialia[J], 2008, 58: 556

11 Abramov V, Abramov O, Bulgakov V et al. Materials Letters [J],
1998, 37: 27

12 Campbell J. International Metallurgical Review[J], 1981(2): 71

13 Zhu H X, Wang J X, Li C et al. Special Casting \& Nonferrous Alloys [J], 2008, 28(7): 522 (in Chinese)

14 Lü S L, Wu S S, Dai W et al. Journal of Materials Processing Technology[J], 2012, 212(6): 1281

\title{
超声功率对 Mg-3RE-3Zn-0.7Y 合金组织和力学性能的影响
}

\author{
方晓刚, 吴树森, 赵 立, 吕书林, 安 萍 \\ (华中科技大学 材料成形与模具技术国家重点实验室, 湖北 武汉 430074)
}

\begin{abstract}
摘 要: 如果在铸造过程能够细化含有稀土元素的金属间化合物, 那么稀土镁合金在耐热应用方面将具有巨大的潜力。研究了半固态制 浆过程中不同超声功率的超声振动对 Mg-3RE-3Zn-0.7Y 合金半固态微观组织以及铸态试样力学性能的影响。试验对液相线以上 $20 \sim 40{ }^{\circ} \mathrm{C}$ 镁合金熔体分别施加超声功率为 $800 \mathrm{~W}$ 至 $1200 \mathrm{~W}$ 的超声振动, 振动时间为 $90 \mathrm{~s}$, 结束超声振动温度为液相线以下 $10{ }^{\circ} \mathrm{C}$ 左右。结果表 明, 超声振动可以制备出组织中具有细小圆整的初生 $\alpha-\mathrm{Mg}$ 相的优良半固态浆料, 并且经过超声功率为 $1000 \mathrm{~W}$ 的超声处理后浆料组织 中初生 $\alpha-\mathrm{Mg}$ 晶粒的平均晶粒直径和平均形状系数 $S_{\mathrm{F}}$ 分别为 $55 \mu \mathrm{m}$ 和 0.63 。此外, $1000 \mathrm{~W}$ 超声处理的铸件试样比未经超声处理的试样 抗拉强度提高了 $25.2 \%$, 伸长率提高了 $93.5 \%$ 。可见, 声空化效应和声流效应使超声振动成为一种制备具有细小圆整初生晶粒镁合金半 固态浆料的有效途径。
\end{abstract}

关键词: Mg-3RE-3Zn-0.7Y 合金; 超声功率; 半固态浆料; 组织; 力学性能

作者简介: 方晓刚, 男, 1989 年生, 博士生, 华中科技大学材料成形与模具国家重点实验室, 湖北 武汉 430074, 电话: 027-87556262, E-mail: kellyfox_3026@qq.com 